\title{
Jovens vozes críticas em Odisseia Segunda edição dos Seminários para Novos Críticos da APCT
}

Alexandra Moreira da Silva e Constança Carvalho Homem

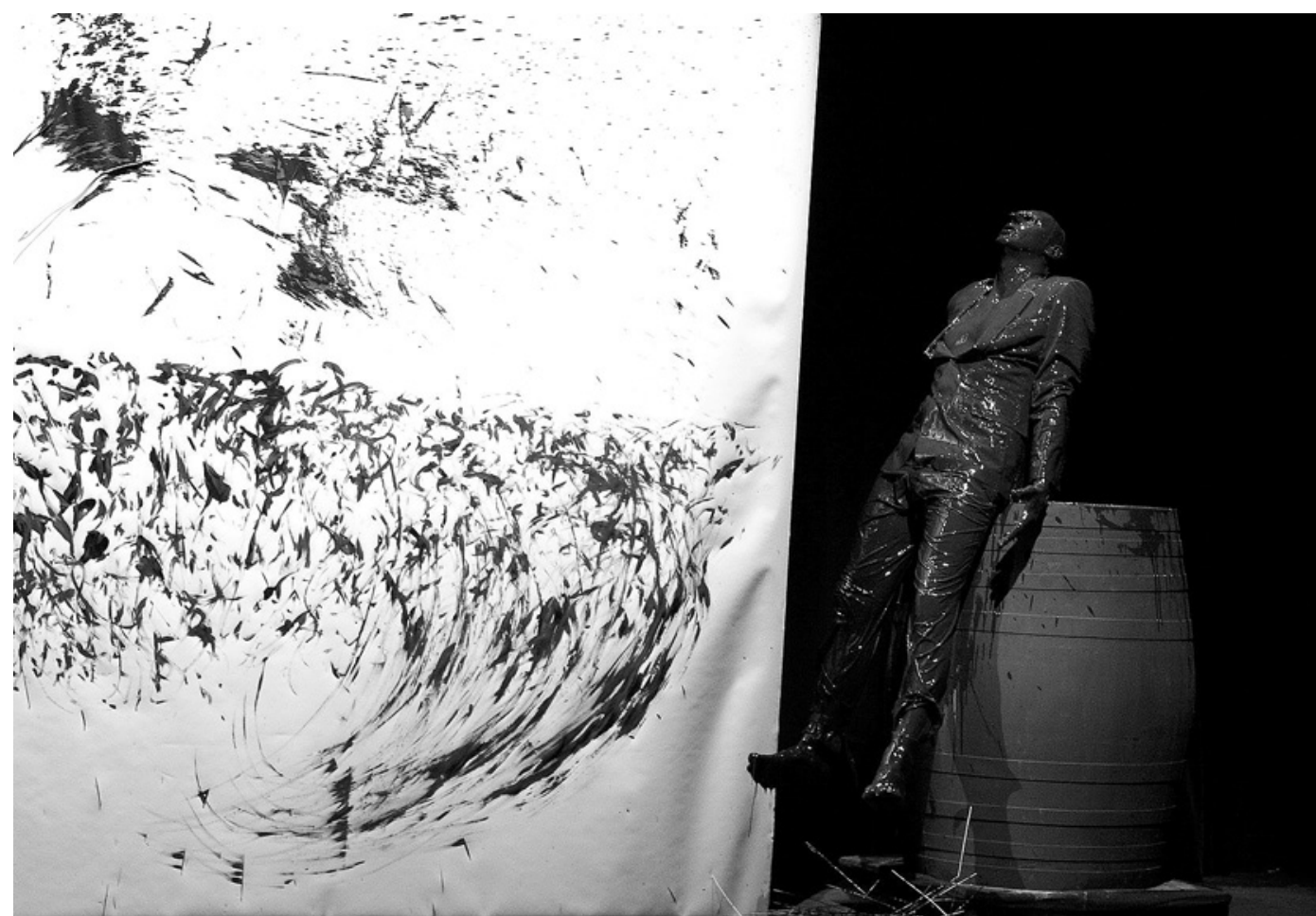

Les corbeaux,

de Josef Nadj e Akosh S, Centre Chorégraphique National d'Orléans e Théâtre Forum Meyrin, Festival Odisseia: Teatro do Mundo 2011 (Josef Nadj), fot. Remi Angeli.

A boleia de uma iniciativa inédita co-organizada pelo Teatro Nacional S. João e por três relevantes estruturas distritais do Norte do pais, o Centro Cultural Vila Flor, o Theatro Circo e o Teatro de Vila Real, a Associação Portuguesa de Críticos de Teatro promoveu no Porto, entre 19 e 22 de Maio de 2011, um segundo Seminário para Novos Críticos '. Agendado de modo a acompanhar o momento de maior recorte da programação, a mostra internacional, o seminário reuniu um conjunto de catorze participantes e três monitores em torno d'as razões do mundo e das razões da crítica.

Foram matéria de discussão os espectáculos Les corbeaux, de Josef Nadj e Akosh S., Médée, de Jean-Louis Martinelli, Je t'appelle de Paris, de Moussa Sanou, e Third Generation, de Yael Ronen, os três últimos seguidos de conversas entre os criadores e o público. Também Saturday Night, de Matthew Lenton, a criação em residência apadrinhada pelo evento (à época ainda em concepção), foi sumariamente discutida, a partir das premissas e do processo expostos em ensaio aberto. Entre consensos e polaridades, num movimento de saudável inquirição, os participantes debruçaram-se sobre os espectáculos em causa e contribuiram para a formulação de um conjunto pertinente de questões: como se comportam os novos formatos face a uma grelha de análise tradicional?; que dificuldades acercam o crítico perante um objecto situado nas zonas, quer limitrofes, quer tangenciais, das várias artes performativas?; em que medida é desejável o socorro de um paratexto - seja nota de balanço ou de intenções - na aferição de um espectáculo que isoladamente não foi uma evidência?; e, não menos importante, como agilizar o necessário distanciamento crítico quando a urgência da temática em cena secundariza a sua efectiva execução?, por outras palavras, até onde é possivel discernir sem que se imponham ao objecto artístico certas "razões do mundo"? A amostra aqui reunida pretende dar conta da experiência presencial e formativa desta Odisseia, em necessário confronto com as questões enunciadas.
0 primeiro decorrera em Guimarães, no âmbito dos Festivais Gil Vicente, sob direcção de Rui Pina Coelho e Rita Martins em Junho de 2010, e dele resultou um artigo de conjunto, "Exercicios de coralidade", publicado na Sinais de cena, n. ${ }^{14}$, de Dezembro de 2010, pp. 87-94. 


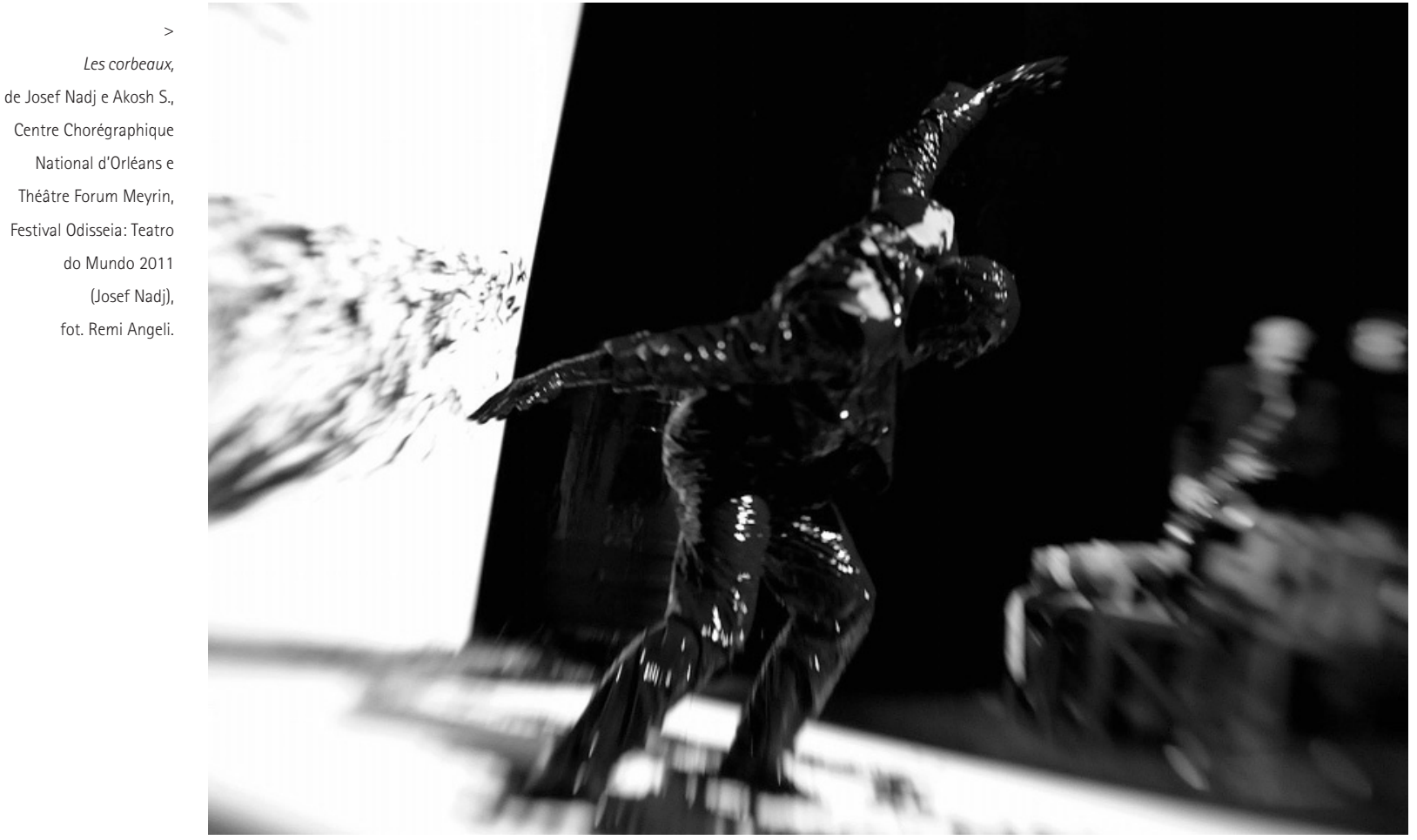

Título: Les corbeaux, de Josef Nadj e Akosh S. Coreografia: Josef Nadj. Direcção musical:Akosh Szelevényi. Desenho de luz: Rémi Nicolas. Cenografia e adereços: Clément Dirat, Julien Fleureau, Alexandre De Monte. Desenho de som: Jean-Philippe Dupont. Interpretação: Josef Nadj, Akosh S. (saxofone e outros instrumentos). Produção:Centre Chorégraphique National d'Orléans e Théâtre Forum Meyrin (Suiça). Local e data de apresentação no Porto (Festival Odisseia: Teatro do Mundo):Teatro Carlos Alberto, 18 e 19 de Maio de 2011.

\section{As metamorfoses de Nadj} Marta Bonito Cunha

É possivel desenhar sem deixar rasto? Nadj procura dizernos que sim, no entanto no palco abandonado pelos intérpretes no final do espectáculo, jazem marcas do corpo corvo-pincel-estátua que oscilava entre a linha do movimento e a do desenho, uma a seguir à outra, uma atropelando a outra, as duas num rond de jambe a terre por vezes unissono. 0 desenho de som resiste um pouco nos ouvidos, e esse sim, acaba por desaparecer. Mas voltará no próximo espectáculo numa nova metamorfose.

Les corbeaux pousou em 2008 num festival de jazz de Paris. No Porto, foi apresentado no âmbito do Festival Odisseia: Teatro do mundo, no mês de Maio de 2011. Não seria de todo despropositado levar esta performance a um festival de dança contemporânea, ou enquadrá-la no universo das artes plásticas... Este hibrido, altamente plástico, resulta da observação de um corvo - símbolo da sabedoria na Hungria -, num telhado em Quioto (Japão).

Marta Cunha Nomeadamente, da observação daquele instante fronteiriço estudou Ciências da

Comunicação na Universidade Nova de Lisboa. Frequenta o

segundo ano de mestrado em Estudos Literários, Culturais Interartes na Faculdade

de Letras da Universidade do Porto. entre o voo e a marcha do pássaro, motivo para abordar o conceito de metamorfose e ritual de passagem. 0 corpoanimal que dança e desenha deixa o seu grasnar a cargo do saxofone e da percussão de Akosh Szelevényi que continuam insistentes e gritantes nos nossos ouvidos mesmo para além da sala de teatro.

0 espectáculo, tendo uma estrutura pré-estabelecida abre-se à improvisação. No palco negro surge lentamente uma luz alaranjada e difusa que ilumina o cenário de toque oriental e os sons de cordas pontualmente quebrados.
Nadj surge em sombra chinesa traçando e entrelaçando linhas na tela que escapam ao seu gesto, numa espécie de prólogo indecifrável do que se passará a seguir. Cai uma certa tensão no público, não se percebe se originada pelos sons desconcertantes se pela estranheza daquela cerimónia que acabou de começar. Já visível e de fato preto, o intérprete lança-se num voo nervoso terrestre: o desenho coreográfico, ora com movimentos infinitamente volumosos e lentos ora com êxtases de velocidade, assina a sua presença efémera no ar e presta depoimento numa segunda tela branca.

0 corpo-corvo torna-se corpo-pincel. Os quadros que vão sendo criados pela impressão do corpo na matéria têm influências de Paso doble, um projecto anterior que Nadj desenvolveu com o artista plástico Miquel Barceló. A imagem do corvo vai-se perdendo e deixa de se ver por completo quando Nadj mergulha num barril de guache preto. É o clímax da fusão do corpo com a matéria. A imagem do corpo-estátua negro, inumano, é de tal forma penetrante que esmaga o que ainda resta da performance. Segue-se mais uma sequência coreográfica, angustiante pela dificuldade que o intérprete tem em respirar. Mas a imagem arrasou tudo, e o antes e o depois do mergulho no poço de tinta traiu e valeu a Les corbeaux. E digo valeu porque é pela plasticidade que o espectáculo se impõe, uma vez que a coerência narrativa parece ainda não ter amadurecido ou, pelo menos, poderia ser melhor explorada.

Les corbeauxé uma improvisação escorregadia entre designações de género que não pede tanto denominações, mas a concepção de todo o quadro apresenta-se numa contínua metamorfose semelhante à do corpo-corvopincel-estátua. 


\section{Cerimónia encantatória}

José Alves de Carvalho

Conta o coreógrafo e bailarino Josef Nadj que um dia, enquanto ensaiava uma performance num telhado de Quioto, no Japão, a sua atenção acabou por se deter num corvo que ali havia pousado. Da observação dessa ave "negra e misteriosa", sinónimo de maus presságios entre nós, mas de sabedoria na Hungria de onde é originário o bailarino, surge a ideia para o espectáculo Les corbeaux, apresentado em Guimarães, Vila Real, Braga e no Porto, no âmbito do Festival Odisseia: Teatro do mundo, três anos após a sua estreia, em 2008, no Théâtre des Bouffes du Nord (Paris).

0 espectáculo - concebido em parceira com o saxofonista Akosh Szelevényi - resultou, porém, de uma encomenda de um festival de jazz o que, desde logo, nos leva a questionar a pertinência da sua apresentação num festival de teatro. Contudo, Les corbeaux não deixará de ser um objecto eventualmente estranho para ambos os públicos, porque a sua natureza - assumidamente multidisciplinar - escapa a catalogações. Dança, performance, música, desenho, instalação... no limite, poderíamos também dizer, poesia.

Até porque Les corbeaux convoca-nos mais enquanto observadores e menos como espectadores. Brilhante como bailarino, Josef Nadj não chama a atenção, não pede que o sigamos. Faz do palco o seu habitat natural, e age, livre, indiferente à presença do público. Chegamos a duvidar se José Nadj encarna esse "pequeno animal preto e misterioso" que tanto admira ou se anseia ser como ele. 0 mergulho final do intérprete no barril de tinta preta sublinha a ideia e acentua a concepção plástica deste espectáculo que, não esqueçamos, surge do interesse que, certo dia, um corvo despertou em Josef Nadj.

Les corbeaux estará talvez nos antípodas do teatro, mas mais do que pôr em causa a sua inclusão neste festival, talvez valesse a pena interrogarmo-nos sobre como seria a reacção do público se 'confrontado com' em vez de 'convidado para' - esta "cerimónia". Será ela tão "encantatória" como a do pássaro que, indiferente à nossa presença, se abeira da janela lá de casa e nos cativa a atenção?

Titulo: Policarpo Quaresma, baseado em Triste fim de Policarpo Quaresma, de Lima Barreto. Adaptação e encenação: Antunes Filho. Cenografia e figurinos: Rosângela Ribeiro. Desenho de luz: Edson FM e Ederson Duarte. Banda sonora: Raul Teixeira. Músicas ao vivo: André de Araújo. Preparação vocal e corporal: Antunes Filho. Assistência de encenação: Michelle Boesche. Interpretação: Adriano Bolshi, André Bubman, André de Araújo, Angélica Colombo, Carlos Morelli, Felipe Hofstatter, Fernando Aveiro, Flávia Strongolli, Freed Mesquita, Geraldo Mário, Ivo Leme, João Gyorgy, Juliana Calderón, Lee Taylor, Marcos de Andrade, Marilia Moreira, Michelle Boesche, Natalie Pascoal, Priscila Gontijo, Rafaela Cassol, Ruber Gonçalves, Ygor Fiori, Walter Granieri. Produção: Centro de Pesquisa Teatral/SESC São Paulo, Grupo de Teatro Macunaíma (São Paulo). Local e data de apresentação no Porto (Festival Odisseia: Teatro do Mundo): Teatro Carlos Alberto, 28 de Maio a 11 de Junho de 2011.

\section{Policarpo Quaresma \\ Cecília Ferreira}

Em 2009, aquando da sua estada no Porto para apresentação de dois espectáculos (Prêt-à-porter e A falecida Vapt-Vupt), Antunes Filho deu uma entrevista ao jornal Vala comum (VC), da Associação de Estudantes da Escola Superior de Música e das Artes do Espectáculos, na qual afirmou: "Eu uso o teatro para aproveitar a alegria de viver." Esta alegria de viver perpassou, indubitavelmente, a vida de Lima Barreto, contaminou a sua personagem Policarpo e continua a fervilhar em Antunes apesar dos seus mais de 80 anos de vida e mais de 60 de carreira. Aos dois homens e à personagem central da peça une-os quase tudo.

Policarpo Quaresma é um anti-herói, um ingénuo nacionalista que, de decepção em decepção, nunca deixa de sonhar com novas sublevações culturais, sociais e políticas, tudo pela identidade da nação: idealista, inteligente, culto, fazedor de auto-utopias e amante incondicional do made in Brasil, começa por querer recuperar o Tupi Guarani como língua oficial do país. Sem sucesso, parte para a aventura desmedida da terra e da agricultura com extravagantes tecnologias, que também fracassa e, finalmente, alista-se no exército para servir a pátria nos primórdios da República, no final do século XIX, ao lado do Marechal Floriano Peixoto, num conturbado periodo de guerra civil provocada pelo autoritarismo e pelos excessos do presidente do Estado, Júlio de Castilhos, que governa o país com mão-de-ferro, apoiado pelo Marechal Floriano. Nunca ninguém levou Policarpo Quaresma a sério, sendo as suas convictas resoluções vistas e tratadas como sandices. E também nunca ninguém levou Lima Barreto a sério, tendo o seu pai enlouquecido por alturas da proclamação da República, facto que o fez conviver muito de perto com a loucura. Uma esmagadora maioria leva Antunes Filho muito a sério e este encara os primeiros com a mesma convicção.

Policarpo Quaresma (2010) fecha a trilogia composta por A falecidade Vapt-Vupt (2009) e Lamartine Babo (2009). Antunes Filhos regressou a Portugal e voltou a convencer o público, que, no final do espectáculo, aplaudiu efusivamente de pé. 0 reconhecimento é partilhado, pois segundo Antunes: "O público é sensacional. É através dele que posso proporcionar socialmente e individualmente a
José Alves de Carvalho é licenciado em Comunicação Social pela Escola Superior de Jornalismo do Porto. jornalista e editor do Jornal Entre margens, ex-director de informação na Rádio Universitária do Minho e antigo jornalista do seguintes meios de comunocação: Rádio Trofa, Rádio Fundação e Semanário de Guimarães.

Cecilia Ferreira é licenciada em Línguas e Literaturas Modernas e em Teatro/Interpretação, mestre em Literaturas Românicas Modernas e Contemporâneas e actriz na Companhia Teatro a Quatro. 


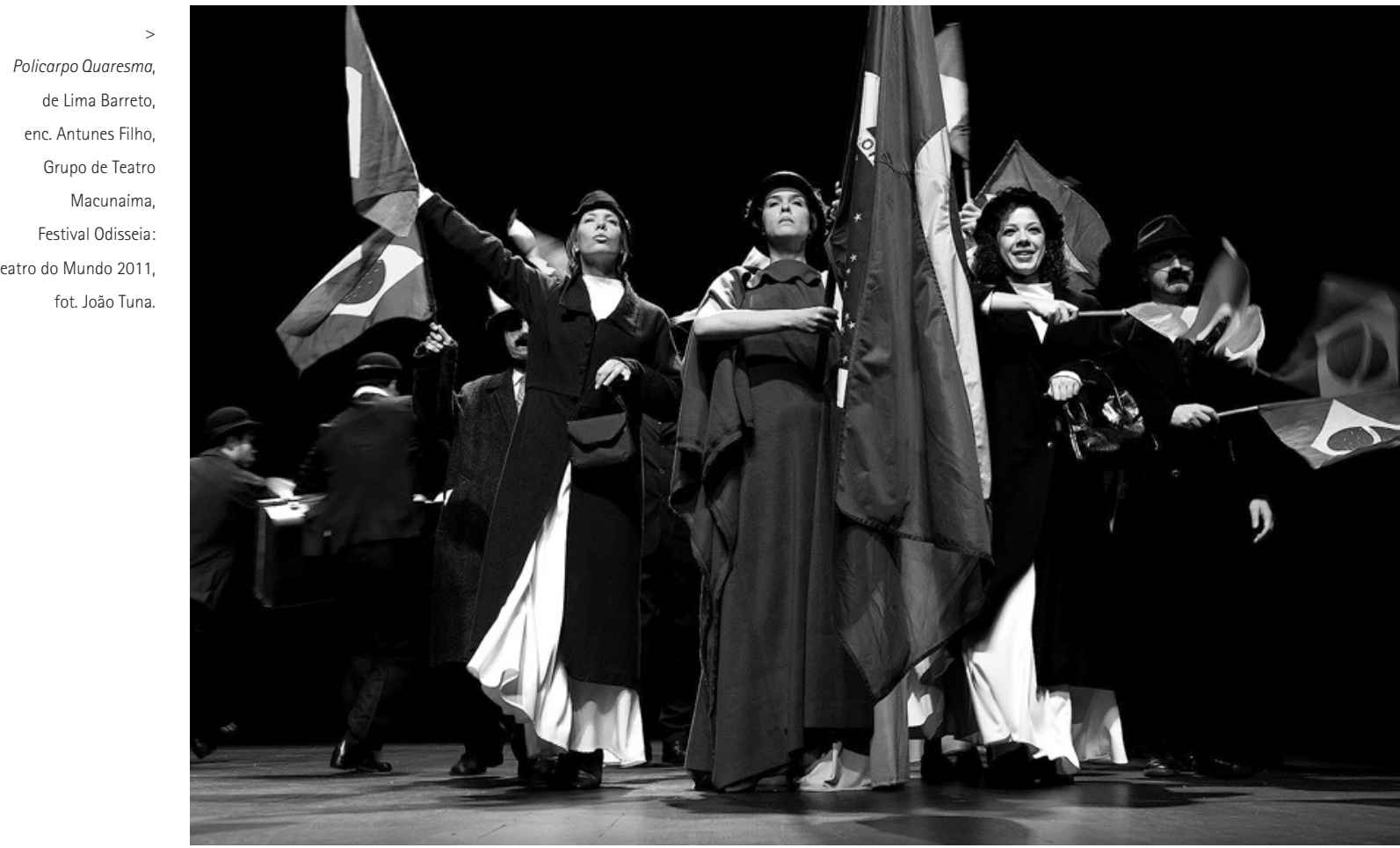

satisfação, a retribuição. Porque eu não sou um, sou todos. Então, eu, no público, procuro dar o sentido da minha vida, a dádiva. Eu posso não gostar de muitas pessoas, mas amo o público" (VC).

Antunes Filho pertence à primeira geração de encenadores brasileiros e participou activamente no movimento de renovação cénica surgido nos anos 60 . Nos anos 80, tornou-se o primeiro encenador a empreender uma obra dramatúrgica e cenicamente autoral, com a montagem de Macunaima (1978). Nos anos 90, deslocou as suas preocupações para o Centro de Pesquisas Teatrais - CPT, grupo de produção, formação e desenvolvimento de novos conceitos e exercícios, para o refinamento de um método próprio de interpretação para o actor. E foi esse refinamento que vimos em palco, apesar da miscelânea de linguagens que o encenador empreendeu (commedia dell'arte, circo, teatro de revista, opereta, comédia de costumes), fruto das inúmeras e diversas influências do seu trabalho: Bob Wilson, Kantor, Kazuo Ohno, expressionismo alemão, psicanálise junguiana, física moderna e, cada vez mais, a filosofia oriental. 0 refinamento, atrás referido, prende-se com o rigor do método. Para o encenador, que gosta de trabalhar com os mesmos actores e cujo trabalho de ensemble é fundamental para o sucesso dos seus espectáculos, 0 desafio dos actores não se restringe ao estudo das personagens, já que a base do seu trabalho é a busca do maior conhecimento possível sobre o universo da peça. Para Antunes Filho, em entrevista concedida ao Diário de S. Paulo: "Se massacrar é obrigar o actor a estudar, a assumir a responsabilidade do momento em que vive, é fazer do actor o senhor dentro do palco e dentro da história em que ele participa, então, nesse sentido, massacro o actor. Eu quero-o independente, eu quero-o senhor absoluto do palco [...] o actor terá que ser ao mesmo tempo cientista, artista, físico, matemático, professor de literatura, político e sociólogo. Pode ser um pouco utópico o que vou dizer, mas o actor será a grande síntese do conhecimento humano. [...] Se mostrar isto tudo ao actor é massacrá-lo, então, eu massacro-o".

Em Policarpo Quaresma, sem precisar de recorrer a dispositivos cénicos, o encenador constrói o cenário com o corpo dos actores, aos quais junta alguns adereços e figurinos. 0 resultado é uma dança de imagens belíssimas, que o coro acentua, completando e comentando com intensa vivacidade e comicidade, não raras vezes trágica, a acção, muito ao jeito brechtiano. Juntos, mais de vinte actores extremamente competentes a nível físico e vocal (para Antunes "corpo e voz são uma coisa só" - VC) constroem um bailado contínuo e contagiante, com muito colorido, música ao vivo, sapateado e um surpreendente jogo cénico, que nos arrebata a cada instante.

E é assim que, de falhanço em falhanço, Policarpo chega ao fim da sua vida sem concretizar absolutamente nada, tal como Lima Barreto nunca viu o seu talento literário verdadeiramente reconhecido enquanto viveu. Antunes, ao adaptar o autor para teatro, nunca se dissociando da função social que o teatro deve ter e sempre embrenhado no estudo da condição humana, assume a sua crítica contra o sucesso dos pobres de espírito e o fracasso dos que ousam, dos que vivem intensamente em busca de alcançar um objectivo válido. Ele critica a inércia do povo, o seu contentamento fácil com o que entretém e inocuamente distrai. Por isso, numa entrevista para o documentário 0 teatro segundo Antunes Filhos - 60, a década das transgressões, o mesmo defende o "Teatro como pensamento, e não como diversão babaca. 0 teatro começa depois que terminou. [...] 0 teatro tem que ser transformador, não que ele transforme em si, mas ele estimula, incita as pessoas a: - Vamos! É corrosivo o teatro". Não deixa de ser curioso que este espectáculo tenha estado no Porto na acesa época das eleições legislativas, na qual dominaram as guerrilhas entre os partidos políticos e em que o povo, já longe do vigor das 

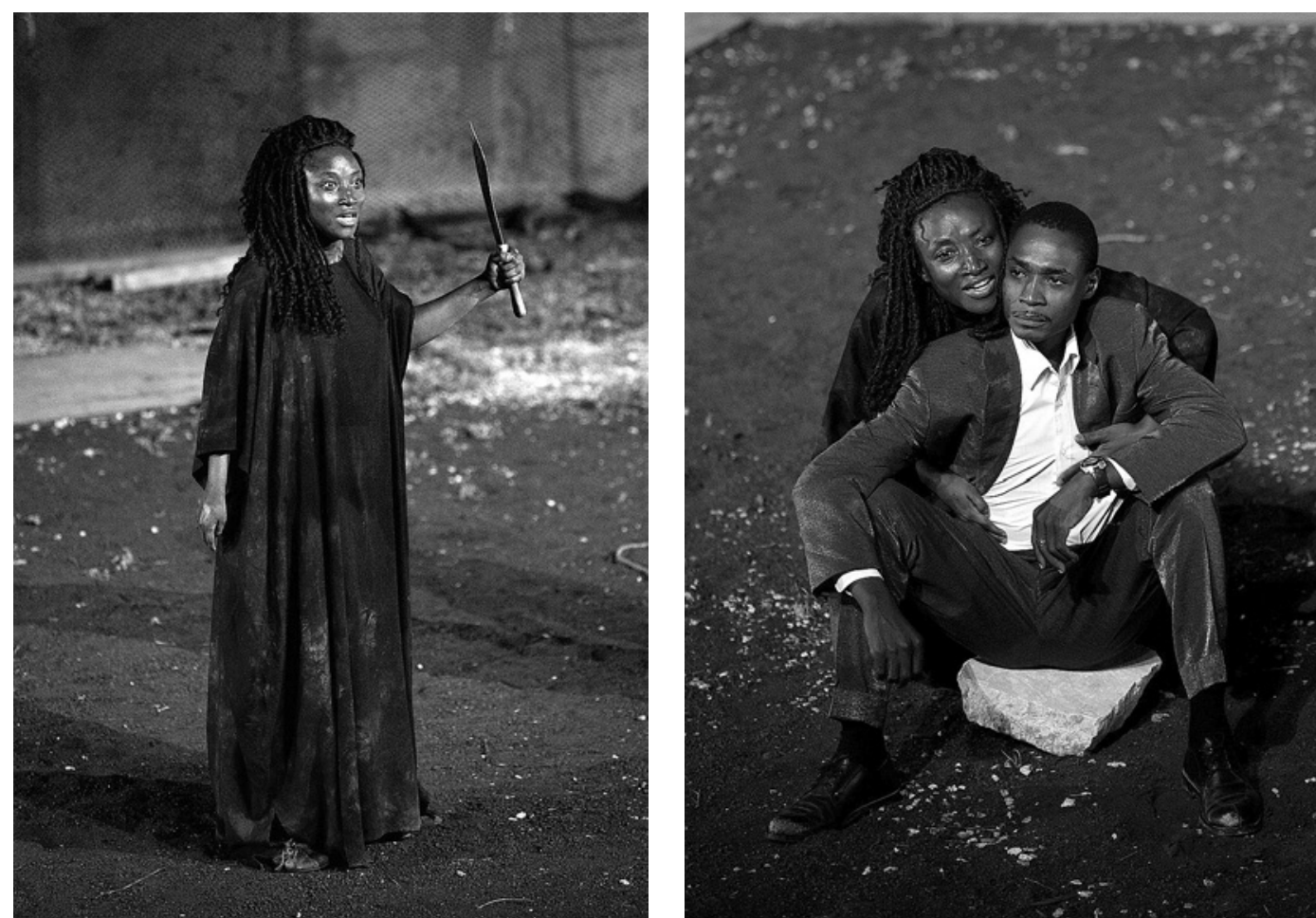

revoluções, não foi quem mais ordenou, sentado na confortável chaise longue da abstenção. Policarpo, irrepreensivelmente interpretado por um dos actores de eleição de Antunes Filho, Lee Taylor, nunca esperou que fossem os outros a agir: Dom Quixote brasileiro, na sua cabeça e na sua ambição de mudar a ordem das coisas, correu o mundo, tentou desfazer injustiças, combateu gigantes e dragões. Passou por situações embaraçosas, penosas, meteu-se em trapalhadas e sofreu com elas, mas nunca desistiu de se aventurar. Os portugueses deviam conhecê-lo.

Antunes devolve a Lima Barreto e a Policarpo Quaresma a sua dignidade. Ele que é o vivo que é reconhecido em vida, o vivo que, sempre que traz o seu trabalho a Portugal, deixa saudades, porque nos transforma, porque nos faz acreditar que se vemos moinhos é porque há moinhos e há que empreender vento para os fazer mover.

Titulo: Médée, de Max Rouquette. Encenação: Jean-Louis Martinelli. Música: Ray Lema. Cenografia: Gilles Taschet. Desenho de luz: Jean-Marc Skatchko. Desenho de som: Philippe Cachia. Figurinos: Patrick Dutertre. Colaboração artística: Florence Bosson. Interpretação: Assetou Demba (coro), Ténin Dembele (coro), Adiaratou Diabate (coro), Yawé Issa Diarra (músico), Haoua Diawara (coro), Bakary Konate (O Velho), Karidia Konate (coro), Mariam Kone (A Velha), Fatimata Kouyate (coro), Nongodo Ouedraogo (Jasão), Odile Sankara (Medeia), Moussa Sanou (Creonte), Blandine Yaméogo (coro) e duas crianças. Produção: Théâtre Nanterre-Amandiers, Napoli Teatro Festival Itália. Local e data de apresentação (Festival Odisseia: Teatro do Mundo):Arcos de Miragaia, 20 a 22 de Maio de 2011.

\section{Medeia torna-se pano de fundo para uma tragédia africana Luiz Carlos Oliveira}

Os tradicionais Arcos de Miragaia, ponto turistico de uma das mais antigas freguesias da cidade do Porto, foi temporariamente um palco. Com troncos servindo como tecto, o chão de terra batida e as suas paredes antigas, teve por cenário o abandono, o descaso, a miséria, lembrando um abrigo para os que o não têm, e onde se viam grandes e velhos pedaços de tecidos que se juntavam para formar a entrada do "palácio". A isto se acrescentavam alguns tambores com água e utensílios domésticos tipicamente africanos.

Neste cenário, tentando manter o fogo, num fogão a lenha improvisado com tijolos e uma grelha, a Ama espera por notícias para a sua Rainha, Medeia, a filha do Sol. Neste local de estrangeiros, a apaixonada rainha, que o encenador Jean-Louis Martinelli escolheu, traz em si os traços fortes da tragédia. Esta Medeia é ainda mais trágica, pois é uma estrangeira negra num pais de negros machistas. Jasão e Creonte são politicos modernos e, trajando os seus fatos impecáveis, representam o poder do homem, em contraste com as mulheres que vestem roupas simples, ou pior, se enrolam em pedaços de pano grosso, e se apresentam de pé descalço, como é o caso das mulheres do coro.

Para representar a adaptação do francês Max Rouquette, Martinelli escolheu um grupo de atores de Burquina Faso, acreditando na intuição de Heiner Müller de que há uma semelhança real entre a essência trágica das personagens do teatro grego antigo e a realidade da vida trágica dos africanos. No entanto, a Medeia africana assume esse valor não por ser uma excelente adapatação, uma formidável montagem ou uma extraordinária encenação do clássico grego de Euripides, mas sobretudo pela proposta, que integra, de discutir aspectos sociais da vida de hoje, o que aumenta ainda mais a carga trágica daquelas personagens.
$<>$

Médée,

de Max Rouquette,

enc. Jean-Louis Martinelli,

Théâtre Nanterre-

Amandiers,

Festival Odisseia: Teatro

do Mundo 2011

(< Odile Sankara;

$>$ Odile Sankara

e Nongodo Ouedraogo), fot. Thêâtre Nanterre-

Amandiers.
Luiz Carlos Oliveira é licenciado em Letras pela Universidade Tuiuti do Paraná. Frequenta, actualmente, o Mestrado em Estudos de Teatro na Faculdade de Letras da Universidade do Porto. É actor e produtor teatral, formado pelo Teatro Lala Schneider no Brasil. 
Mesmo admitindo que Martinelli pegou numa receita fácil para encenar a adaptação - de resto, não muito interessante - de Rouquette, a verdade é que transformou o todo num espectáculo de grande qualidade, aproximando ainda aquele universo humano, que não abandona os seus costumes, da posição de Medeia que também não nega a sua paixão e seu sofrimento.

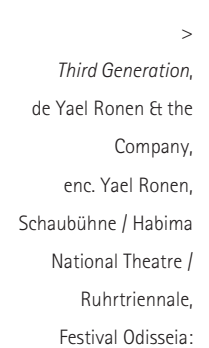

Teatro do Mundo 2011 ,

fot. Heiko Schäfer.

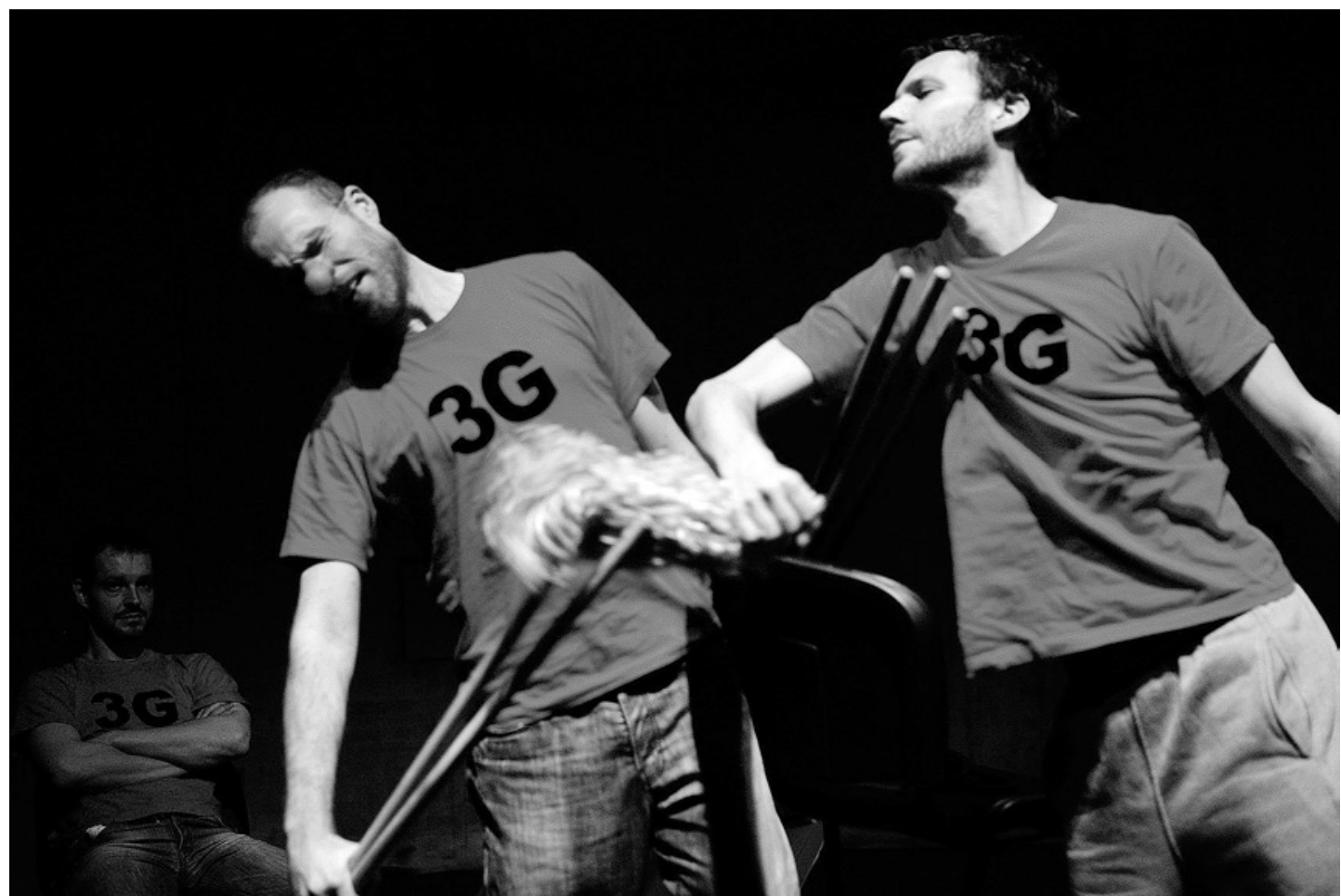

Titulo: Third Generation, de Yael Ronen \&t the Company. Encenação:Yael Ronen. Dramaturgia: Amit Epstein, Irina Szodruch. Interpretação: Tamar Ben Ami, Knut Berger, Niels Bormann, Ishai Golan, George Iskandar, Matthias Matschke, Orit Nahmias, Rawda, Judith Strößenreuter, Yusef Sweid. Produção: Schaubühne (Berlim), Habima National Theatre (Telavive), Ruhrtriennale 2009. Local e data de apresentação no Porto (Festival Odisseia: Teatro do Mundo):Teatro Nacional S. João, 20 e 21 de Maio de 2011.

\section{A terceira geração Susana Chicó}

A jovem encenadora Yael Ronen de Israel trouxe ao Festival Odisseia a terceira geração provinda dos sobreviventes

Susana Chicó (n. 1985) tem feito seu percurso pessoal,

académico e

profissional entre fotografia e o teatro.

Actualmente frequenta

o mestrado de Estudos de Teatro (FLUL)

trabalha em

investigação no Chapitô. do holocausto pondo em palco uma contenda entre alemães, judeus e árabes israelitas. As luzes da plateia estão ainda acesas quando um dos actores, loiro e de pele muito branca, entra na sala com boa disposição para nos informar que o espectáculo a que vamos assistir é ainda um trabalho em curso. Em seguida, pergunta-nos se há judeus, ciganos ou homossexuais na plateia pedindo depois desculpa às poucas pessoas que levantaram o braço. Desculpa-se pelo Holocausto e pelas acções dos seus avós em tom despropositadamente prestável e ensaiado, como uma ladainha que vem entoando desde sempre.
Um elenco multinacional (alemães, judeus e árabes israelitas) cromaticamente uniformizado por t-shirts vermelhas onde se lê o acrónimo "3G" é colocado em pé de igualdade e todos se apresentam e às suas convicções com humor e sem apelar a personagens. Recorrendo a uma estratégia interpretativa jovial e brincalhona que cruza a dramaterapia com a mímica e o fantoche, é astuciosamente infantilizada a herança da culpa, da vitimização e da indignação que tolda esta terceira geração suavizando-se desta forma a controvérsia e as hostilidades. A não ficção é neste espectáculo adoptada como forma directa de questionamento e desafio e se para chorar temos de nos envolver, para rir temos de nos distanciar. 0 distanciamento da terceira geração revela-se aqui, provocatoriamente e sem pretensões, através do humor e de uns poucos momentos mais tensos, revelando que o tempo não curou ainda feridas antigas. 